\title{
Determination of bioactive properties of food grade extracts from Icelandic edible brown seaweed sugar kelp (Saccharina latissima) with in vitro human cell cultures (THP-1).
}

\author{
Magdalena M. Stefaniak-Vidarsson'1, María Gudjónsdóttir ${ }^{1}$, Gudrun Marteinsdottir ${ }^{2,3}$, \\ Sesselja Omarsdottir ${ }^{4}$, Elena Bravo ${ }^{5}$, Olafur E. Sigurjonsson ${ }^{6,7}$, Kristberg \\ Kristbergsson ${ }^{1,3 *}$
}

${ }^{1}$ Faculty of Food Science and Nutrition, School of Health Sciences, University of Iceland; ${ }^{2}$ School of Engineering and Natural Sciences, University of Iceland; ${ }^{3}$ TARAMAR Ltd ${ }^{4}$ Faculty of Pharmacy, School of Health Sciences, University of Iceland; ${ }^{5}$ Department of Cell Biology and Neurosciences, Istituto Superiore di Sanità, Rome, Italy; ${ }^{6}$ The Blood Bank, Landspitali University Hospital, Reykjavik, Iceland; ${ }^{7}$ School of Science and Engineering, Reykjavik University, Reykjavik, Iceland

Corresponding author: Kristberg Kristbergsson, $\mathrm{PhD}$, professor, Faculty of Food Science and Nutrition, School of Health Sciences, University of Iceland, Saemundargata 6, 101 Reykjavik, Iceland and Director of R and D TARAMAR Ltd, Midnestorg 3, 245 Sandgerdi, Iceland

Submission Date: August 22 ${ }^{\text {nd }}, 2018$, Acceptance Date: January $28^{\text {th }}, 2018$, Publication Date: January $31^{\text {st }}, 2018$

Citation: Stefaniak-Vidarsson M.M., Gudjónsdóttir M., Marteinsdottir G., Omarsdottir S., Bravo E., Sigurjonsson O.E., Kristbergsson K. Determination of bioactive properties of food grade extracts from Icelandic edible brown seaweed sugar kelp (Saccharina latissima) with in vitro human cell cultures (THP-1). Functional Foods in Health and Disease 2019; 9(1): 1-15. DOI: https://doi.org/10.31989/ffhd.v9i1.546

\footnotetext{
ABSTRACT

Background: Sugar kelp (Saccharina latissima, formerly known as Laminaria saccharina) is a brown seaweed which naturally occurs in the North Atlantic. Seaweeds may be one of the last natural food resources abundantly available. They are known to contain many compounds which may have additional functional benefits. This edible seaweed is characterized by high content of nutrients including carbohydrates and polyphenols, which are recognized antioxidants. Because their natural environment is a 3\% saline solution, they are very resistant to mild extraction methods. However, extracts from solvent extractions usually contain residual solvents, making them unacceptable for high quality functional foods and high end cosmetics. The objective of this study was to test the biological properties of three extracts from sugar kelp (Saccharina latissima).
} 
Methods: Cold water, hot water, and ethanol: water (70:30 v/v) extracts were prepared. Total Carbohydrate Content (TCC) was determined by the phenol - sulphuric acid method and values were expressed as $\mathrm{mg}$ of fucose/g of dry extract. Total Polyphenol Content (TPC) was determined and expressed as mg of Gallic Acid Equivalent (GAE)/100g of dry extract. Oxygen Radical Absorbance Capacity (ORAC) assay was performed for all extracts and values were expressed as $\mu \mathrm{M}$ of Trolox ${ }^{\circledR}$ Equivalent/g of dry extract. Human leukemia monocytic cell line (THP-1) was used to investigate the bioactivity of Saccharina extracts. Extracts were applied to PMA differentiated THP-1 cells. Cytotoxicity of derived extracts was assessed by light microscopy followed by XTT proliferation assay. Enzyme-linked Immunosorbent assays (ELISA) were performed to determine secretion of interleukin - 10 (IL-10), tumor necrosis factor $-\alpha($ TNF- $\alpha)$ and interleukin -6 (IL-6).

Results: The cold water extract exhibited very toxic properties toward macrophages and was thereby excluded from the experimental proceedings with use of the macrophages. Among all the tested extracts, the hot water extract was richest in sugars $(682 \pm 243 \mathrm{mg}$ fucose/g dry extract) and polyphenols (96.5 $\pm 5.6 \mathrm{mg} \mathrm{GAE} / \mathrm{g}$ dry extract), which was correlated to the determined ORAC values $(1686 \pm 99 \mu \mathrm{M} \mathrm{TE} / \mathrm{g}$ dry extract). The addition of hot water and ethanol extracts at concentrations $100 \mu \mathrm{g} / \mathrm{ml}$ triggered secretion of pro-inflammatory cytokine TNF- $\alpha$ suggesting immunomodulatory properties of Saccharina extracts toward macrophages.

Conclusions: The present study suggests that carbohydrate enriched extracts from Icelandic edible seaweed Saccharina latissima have antioxidant and immunomodulatory properties towards human THP-1 derived macrophages. The carbohydrate and polyphenol correlated with ORAC values confirming antioxidant properties of the derived extracts. The hot water extract affected the pro-inflammatory $(\mathrm{TNF}-\alpha)$ and anti-inflammatory (IL-10) cytokine secretion in macrophages, suggesting their bioactivity through immunomodulatory actions and can be considered for practical applications in functional foods and cosmetics.

Keywords: Seaweeds, Saccharina latissimi, bioactivity antioxidants, immunomodulation

\section{INTRODUCTION}

Marine macro algae have been widely consumed for centuries and is a recognized source of food [1]. In Iceland, selected seaweed species like dulse (Palmaria palmata) are a part of the traditional diet, providing various components such as iodine and vitamin $\mathrm{C}$. However, despite progress in research on the composition and nutrition of macro algae, there is a lack of information on the impact of seaweed bioactivity on the human body.

Seaweeds are classified into three groups based on their photosynthetic pigmentation: brown algae (Phaeophyta), red algae (Rhodophyta), and green algae (Chlorophyta) [2]. Seaweed groups vary in nutritional and chemical composition containing different levels of constituents such as proteins, lipids, carbohydrates, ash, minerals, and fibers [3-5].

Sugar kelp (Saccharina latissima, previously known as Laminaria saccharina and Fucus saccharinus) is a brown seaweed that commonly occurs in the North Atlantic, including rocky shores of Iceland [6]. In the past, wild grown kelps were harvested directly from the sea. Today, sugar kelp is farmed on ropes and is commercially available throughout the year. Sugar kelp has been appreciated in Japanese cuisine for its sweet flavor, mineral abundance (calcium, 
potassium, manganese, iron), and iodine content [7, 8]. Furthermore, Saccharina is a recognized source of polysaccharides including fucoidans, alginates, and laminarans exhibiting several bioactives properties [9]. Sugar kelp also contains phlorotannins (polyphenols) but their content is not as high compared to other brown seaweed species like Fucus vesiculosus and Fucus serratus [1, 10]. However, despite its richness in nutrients, Fucus is not tasty and therefore undesirable in foods. Saccharina latissima is more palatable due to its high carbohydrate content, having wide applications for foods [7].

In addition to its nutritional properties, Saccharina may also provide numerous phytochemicals that could have applications outside the food sector, including medical and cosmetic [11]. Polysaccharides and polyphenols present in brown algae have been recognized as beneficial to health due to their antioxidant, anti-inflammatory, anti-angiogenic, and anticancer properties [2].

For the past decade, the chemical composition of macro algae has been investigated, providing valuable information on seaweed constituents [3, 12, 13]. Various research methods have been used to determine bioactive properties of macro algae including in vitro models using human derived cell lines like Hep - 29 (liver model), Caco-2 (small intestine), or THP 1 (immune responses). Macrophage cell model (THP - 1) is a cell model commonly used to investigate the bioactivity of food and pharmaceutical compounds [14].

Macrophages are monocyte derived cells with a great capacity for phagocytosis of dying cells and various pathogens [15]. This feature makes macrophages a key player in the innate immune system. Activated macrophages secrete a range of cytokines that involve other cells to initiate responses from an adaptive immune system [16].

Cytokines are small extracellular signaling peptides and glycoproteins that modulate the immunological responses including inflammation [17]. A well-known cytokine is the tumor necrosis factor $-\alpha(\mathrm{TNF}-\alpha)$ which is an early response pro-inflammatory cytokine followed by secretion of pro - inflammatory cytokine interleukin - 6 (IL-6) and later by secretion of anti-inflammatory cytokines including interleukin - 10 (IL - 10) [18].

Despite recent progress in seaweed research, there is still little data on the potential effects of seaweed derived compounds on human macrophages. The purpose of this study was to evaluate bioactivity and chemical properties of food grade water and ethanol based extracts derived from Icelandic edible brown seaweed Saccharina latissima (sugar kelp) to improve understanding of marine macro algae properties with respect to human health, especially the immune system. The extracts were further evaluated with methods used conventionally to evaluate antioxidant activity like oxygen radical absorbance capacity (ORAC) assay, total polyphenol content (TPC) and total carbohydrate content (TCC).

\section{METHODS AND MATERIALS}

\section{Reagents}

Dried sugar kelp harvested between May and July (Saccharina latissima) was purchased from Icelandic Blue Mussel and Seaweed ehf. (Stykkisholmur, Iceland). Ethanol 96\% (\#24105), phenol (\#P1037), sulphuric acid 95 - 97\% (\#07208), L - fucose (\#F2252), Folin and Ciocalteu's phenol reagent (\#F9252), anhydrous sodium carbonate (\#31432), gallic acid (\#G7384), fluorescein (\#46960), 2,2'-Azobis(2-methylpropionamidine) dihydrochloride (AAPH) (\#440914), ( \pm )-6-Hydroxy-2,5,7,8-tetramethylchromane-2-carboxylic acid (Trolox®) (\#238813 ), phorbol 12 - myristate 13 - acetate (PMA) (\#P1585) and 2- mercaptoethanol 
(\#M3148) were purchased from Sigma - Aldrich Chemie GmbH (Steinheim, Germany). THP - 1 cell line (\#ATCC TIB - 202) was purchased from LGC Standards GmbH (Wesel, Germany). Sterile $10 \mathrm{mM}$ phosphate buffer saline (PBS) without magnesium and calcium, $\mathrm{pH}$ = 7.4 (\#10010-056), RPMI 1640- GlutaMAX ${ }^{\mathrm{TM}}$ culture medium (\#61870-150) and Trypan Blue 0.4\% staining solution (\#15250-061), Penicillin -Streptomycin (\#15140-122), Fetal Bovine Serum (FBS) (\#10500-064) were purchased from Invitrogen (Paisley, UK). 2,3-Bis (2methoxy-4-nitro-5-sulfophenyl)-2H-tetrazolium-5-carboxanilide (XTT) proliferation assay (\#30-1011K ) from (ATCC, Manassas, VA). Human ELISA TNF - $\alpha$ (\#900-K25), IL-10 (\#900-K21), IL - 6 (\#900-K16), and ELISA buffer kit (\#900-K00) were purchased from Peprotech EC Ltd. (London, UK).

\section{Cold water extraction}

Cold water extraction was prepared to imitate raw food. A sample of $10 \mathrm{~g}$ of dried Saccharina was rinsed three times with deionized water and minced into pulp in a food processor (Braun CombiMax 600, Germany) for 2 min. The pulp was transferred together with $1000 \mathrm{ml}$ of deionized water to a $2000 \mathrm{ml}$ Erlenmeyer flask wrapped in aluminum foil to minimize exposure to light which was placed on a platform shaker for $3 \mathrm{~h}$ at room temperature. All samples were in triplicates and the solution was collected in $50 \mathrm{ml}$ polypropylene tubes with screw caps (\#430291, Corning, UK) and centrifuged (centrifugeTJ20, Beckman Coulter, CA) for 15 min at $3000 \mathrm{rpm}$. The supernatant was transferred into aluminum trays for freezing $\left(-20^{\circ} \mathrm{C}\right)$ prior to lyophilisation (Heto model FD2.5, Heto Lab Equipment, Allerød, 114 Denmark).

\section{Hot water extraction}

Hot water extraction was prepared using commonly available cooking recipes including edible seaweed species. A sample of $10 \mathrm{~g}$ of dried seaweed was rinsed three times with deionized water. The rinsed seaweed was then minced into pulp in a food processor (Braun CombiMax 600 , Germany) for $2 \mathrm{~min}$. The pulp was transferred together with $1000 \mathrm{ml}$ of deionized water to a $2000 \mathrm{ml}$ Erlenmeyer flask wrapped in aluminum foil to minimize exposure to light and placed in a water bath preheated to $95^{\circ} \mathrm{C}$ and kept at $95^{\circ} \mathrm{C}$ for $30 \mathrm{~min}$. Then the solution was brought to room temperature and the liquid with tissue material was collected and centrifuged for $15 \mathrm{~min}$ at $3000 \mathrm{rpm}$ (centrifuge TJ20, Beckman Coulter, CA). Supernatants were frozen at $-20{ }^{\circ} \mathrm{C}$ followed by lyophilisation (Heto model FD2.5, Heto Lab Equipment, Allerød, 114 Denmark).

\section{Ethanol extraction}

Ethanol extraction was performed to imitate process of marinating in high percentage alcohol. A sample of $10 \mathrm{~g}$ of dried seaweed was rinsed 3x with ion exchanged water followed by 2 min mincing in a food processor. The pulp was transferred into $1000 \mathrm{ml}$ Erlenmeyer flask and 250 $\mathrm{ml}$ of $70 \%$ ethanol was added into a pre-prepared sample. The flask was wrapped in aluminum foil and placed on shaker at room temperature for $24 \mathrm{~h}$. After the incubation, liquid and algal tissue remains were collected and centrifuged as described above. The volume of collected supernatant was decreased by rotary evaporation at $42^{\circ} \mathrm{C}$ and then transferred to a freezer at $80^{\circ} \mathrm{C}$, rather than the $-20^{\circ} \mathrm{C}$ like the water extracts due to the low freezing point of ethanol, and later freeze dried (Heto model FD2.5, Heto Lab Equipment, Allerød, Denmark) 


\section{Determination of Total Carbohydrate Content (TCC)}

The Total Carbohydrate Content (TCC) of the extracts was determined by phenol-sulphuric acid method optimized for microplate by Masuko, Minami [19]. A sample of $10 \mathrm{mg}$ of seaweed extracts were dissolved in $1 \mathrm{ml}$ of distilled water. Standards were prepared at concentration range 0 to $1 \mathrm{mg} / \mathrm{ml}$ of $\mathrm{L}-$ fucose. An aliquot of $50 \mu \mathrm{l}$ of sample or standard were added into PureGrade 96-well flat bottom transparent microplate (\#781602, Brand $\mathrm{GmbH}+\mathrm{CO} \mathrm{KG}$, Wertheim, Germany) followed by immediate addition of $150 \mu \mathrm{l}$ of sulphuric acid (96\%) and $30 \mu \mathrm{l}$ of phenol (5\%). The plate was placed for $5 \mathrm{~min}$ into an incubator preheated to $90{ }^{\circ} \mathrm{C}$. After incubation the plate was cooled to ambient temperature and the absorbance was measured at $490 \mathrm{~nm}$ in a Multiskan Spectrum spectrometer (Thermo Fisher Scientific, Marietta, OH). The results were expressed as mg of fucose/g extract.

\section{Estimation of Total Polyphenol Content (TPC)}

The total polyphenol content (TPC) was determined by modified method of Turkmen, Velioglu [20]. A $10 \mathrm{mg}$ sample of pulverized extract were dissolved in $1 \mathrm{ml}$ of distilled water. An aliquot of $20 \mu 1$ sample was mixed with $20 \mu \mathrm{l}$ of gallic acid standard and then mixed with $100 \mu \mathrm{l}$ of Folin and Ciocalteu's phenol reagent (10\% in distilled water) in PureGrade 96-well flat bottom transparent microplate (\#781602, Brand $\mathrm{GmbH}+\mathrm{CO}$ KG, Wertheim, Germany). After 5 minutes, $80 \mu \mathrm{l}$ of $7.5 \% \mathrm{Na}_{2} \mathrm{CO}_{3}$ solution was added. The plate was incubated for 30 minutes at $40^{\circ} \mathrm{C}$ and the absorbance was measured in $\mathrm{b}$ at $700 \mathrm{~nm}$. Total polyphenol content was determined from a standard curve and expressed as grams of gallic acid equivalent (GAE) per $100 \mathrm{~g}$ of dry extract.

\section{Determination of Oxygen Radical Absorbance Capacity (ORAC)}

Both extracts were analyzed using a modified ORAC assay based on the method described by Ganske and Dell [21]. A $150 \mu \mathrm{l}$ aliquot of $10 \mathrm{nM}$ fluorescein was added into PureGrade 96well flat bottom transparent microplate (\#781602, Brand GmbH + CO KG, Wertheim, Germany), followed by addition of $25 \mu$ of Trolox ${ }^{\circledR}$ or sample with ice cold $25 \mu 1120 \mathrm{nM} 2,2^{\prime}$ Azobis(2-methylpropionamidine) dihydrochloride (AAPH). After adding AAPH, the plate was immediately placed into preheated $37{ }^{\circ} \mathrm{C}$ SpectraMax M3 Multi-Mode Microplate Reader (Molecular Devices, CA) and shaken for 15 seconds before measurement was initiated. Readings were performed at $1 \mathrm{~min}$ intervals for $80 \mathrm{~min}$ at $37{ }^{\circ} \mathrm{C}$ at $485 \mathrm{~nm}$ excitation and 580 $\mathrm{nm}$ emission. A $515 \mathrm{~nm}$ cut-off filter was used for emission for signal improvement. ORAC calculations were performed using the SoftMax Pro software (Molecular Devices, CA) which was integrated in the microplate reader calculation tool. (Molecular Devices, CA). ORAC values were expressed as $\mu \mathrm{M}$ of Trolox $^{\circledR}$ Equivalent (MTE)/ $\mathrm{g}$ of dry extract using the calibration curve for Trolox ${ }^{\circledR}$.

\section{Cell culture}

Cell culture experiments were carried out with THP - 1 human monocytic cell line (\#ATCC TIB - 202, LGC Standards GmbH, Wesel, Germany) in RPMI GlutaMAX ${ }^{\mathrm{TM}}$ medium supplemented with Penicillin/Streptomycin, 10\% fetal bovine serum (FBS) and $20 \mu \mathrm{M} 2-$ mercaptoethanol in the incubator (Thermo Forma 311 Model, Thermo Electron Corporation, Marietta, $\mathrm{OH})$ at $37^{\circ} \mathrm{C}, 5 \% \mathrm{CO}_{2}$, and $95 \%$ humidity. To differentiate monocytes into macrophages the monocytes were seeded in 12-well plates (\#351143, Beckton Dickinson 
Labware Europe, Le Pont de Claix, France) at a density of $0.6 \times 10^{6}$ cells $/ \mathrm{ml}$ of complete growth medium and $200 \mathrm{ng} / \mathrm{ml}$ phorbol 12-myristate 13-acetate (PMA) was added into the culture media followed by $72 \mathrm{~h}$ incubation. After the incubation with PMA, cells were washed twice with pre-warmed $10 \mathrm{mM}$ phosphate buffer saline (PBS) without magnesium and calcium, $\mathrm{pH}$ $=7.4$. Hot water and ethanol extracts were dissolved in media and placed under UV light for $20 \mathrm{~min}$ followed by centrifugation at $3000 \mathrm{rpm}$ for $10 \mathrm{~min}$ (Thermo Scientific Heraeus Multifuge X3, Thermo Electron LED GmbH, Osterode, Germany). Prepared solutions were diluted and added to wells at concentration range ( 0 to $1000 \mu \mathrm{g} / \mathrm{ml})$ for $24 \mathrm{~h}$ incubation. After incubation, the cells were examined and possible cytotoxicity was pre-determined by light microscopy.

\section{Cell viability assessment}

THP-1 cells were seeded in 96-well flat bottom transparent micro plate Microtest ${ }^{\mathrm{TM}}$ (\#351172, Beckton Dickinson Labware Europe, Le Pont de Claix, France) at density of 5 x $10^{4}$ cells per well and differentiated into macrophages with the same procedure as described above. Hot water and ethanol extracts were added to differentiated cells (THP-1 macrophages) at five concentrations: $0,1,10,100,500$ and $1000 \mu \mathrm{g} / \mathrm{ml}$ followed by $24 \mathrm{~h}$ incubation. Cell viability was pre-assessed by light microscopic analysis and followed by 2,3-Bis (2-methoxy-4-nitro5-sulfophenyl)-2 $H$-tetrazolium-5-carboxanilide (XTT) proliferation assay (ATCC, Manassas, VA) according to manufacturer's instructions.

\section{Enzyme Linked Immunosorbent Assay (ELISA)}

After incubation the medium was collected, centrifuged at $3500 \mathrm{rpm}$ (Centrifuge 5415R, Eppendorf AG, Hamburg, Germany) to remove cellular debris, and stored at $-80{ }^{\circ} \mathrm{C}$ until further analysis. The secretion of TNF- $\alpha$, IL-6 and IL-10 was determined in Multiskan Spectrum spectrometer (Thermo Fisher Scientific Inc, Marietta, OH) by ELISA following manufacturer's instructions (Peprotech EC Ltd., London, UK).

\section{Statistical analysis}

Data were reported as the mean of the experiments plus/minus standard error of the mean (SEM). Each experimental condition was performed in triplicate. Data was analyzed by oneway analysis of variance (ANOVA) and SigmaStat 9.0 (Systat Software, San Jose, CA). Significant differences in the means between groups were calculated using the Holm - Sidak multiple comparison which, according to SigmaStat, has more power than Bonferroni and Tukey.

\section{RESULTS AND DISCUSSION \\ Total Carbohydrate Content (TCC)}

TCC was highest $(\mathrm{p}<0.05)$ in the hot water extracts from Saccharina latissima at $682 \pm 243 \mathrm{mg}$ carbohydrate/g extract while the cold water and ethanol extracts were less rich in carbohydrates at $512 \pm 182 \mathrm{mg}$ carbohydrate/g dry extract and $294 \pm 108 \mathrm{mg}$ carbohydrate/g dry extract respectively (Table 1). Carbohydrate accumulation in seaweed tissue has been reported to be at its highest during the summer months [22]. For that reason, our extracts were prepared from Saccharina latissima harvested between May and July. The extraction conditions were 
designed to imitate home cooking. Hot water extraction simulated simmering while preparing meals with seaweeds as a food ingredient, usually requiring about 30 minutes of cooking. The high water temperature helped rupture cell walls increasing extraction efficacy. The TCC content of Saccharina latissima has, to the best of our knowledge, not been reported but previous studies have shown that increased polarity of the extraction solvent resulted in increased yields for extracted carbohydrates for another type of brown seaweed (Saccharina siliquastrum) [23].

Table 1. Chemical properties of Saccharina extracts

\begin{tabular}{llll}
\hline $\begin{array}{l}\text { Extracts from } \\
\text { Saccharina }\end{array}$ & $\begin{array}{l}\text { Total Carbohydrate } \\
\text { Content }\end{array}$ & $\begin{array}{l}\text { Total Polyphenol } \\
\text { Content }\end{array}$ & $\begin{array}{l}\text { Oxygen Radical } \\
\text { Absorbance } \\
\text { Capacity }\end{array}$ \\
& $\begin{array}{l}\text { (mg fucose/g dry } \\
\text { extract) }\end{array}$ & $\begin{array}{l}(\mathrm{mg} \mathrm{GAE} / 100 \mathrm{~g} \text { dry } \\
\text { extract })\end{array}$ & $\begin{array}{l}(\mu \mathrm{M} \mathrm{T.E} / \mathrm{g} \text { dry } \\
\text { extract) }\end{array}$ \\
\hline $\begin{array}{l}\text { Cold water } \\
\text { extract }\end{array}$ & $512 \pm 182^{\mathrm{a}}$ & $32 \pm 3^{\mathrm{a}}$ & $259 \pm 37^{\mathrm{a}}$ \\
$\begin{array}{l}\text { Hot water } \\
\text { extract }\end{array}$ & $682 \pm 243^{\mathrm{b}}$ & $97 \pm 6^{\mathrm{b}}$ & $1686 \pm 99^{\mathrm{b}}$ \\
Ethanol extract & $294 \pm 108^{\mathrm{c}}$ & $38 \pm 6^{\mathrm{a}}$ & $1177 \pm 109^{\mathrm{c}}$ \\
\hline
\end{tabular}

${ }^{a}$ Values are mean \pm standard deviation. Means within a column followed by the same letter are not significantly $(\mathrm{p}>0.05)$ different

\section{Total Polyphenol Content (TPC)}

The hot water extract showed the highest $(\mathrm{p}<0.001)$ TPC at $97 \pm 6 \mathrm{mg}$ GAE/100g dry extract compared to $32 \pm 3 \mathrm{mg}$ GAE$/ 100 \mathrm{~g}$ dry extract for cold water extract and $38 \pm 6 \mathrm{mg}$ GAE/100g dry extract for the ethanol extracts (Table 1). However, the difference was not significant between cold water and ethanol extract $(\mathrm{p}=0.226)$. As previously reported, the type of solvent and extraction temperature have a significant impact on TPC where acetone at $56^{\circ} \mathrm{C}$ has been reported to give the best results $[10,24]$. Similar to the carbohydrate extraction, both higher temperature and increased solvent polarity increased efficiency for extracted polyphenols. Despite the unquestionable advantage of acetone over other solvents such as water or ethanol with respect to concentration of extracted compounds, a decision was made for this study to use water and $70 \%$ of ethanol to minimize toxicity of the extracts due to the possibility of presence of organic solvent residues in the extracts which may be harmful to the in vitro macrophage culture used to evaluate bioactivity. Additionally, the demands from end-users of bioactives in functional foods and cosmetics are increasingly towards non organic solvent extracts or extracts that are fully food grade. 
As expected, TPC in all three extracts was lower compared to other brown seaweed species such as Fucus vesiculosus or other representatives from the family Fucaceae [1]. The polyphenol content was reported to vary between seaweed species and exhibit seasonal variation, with the highest peak during the summer and early autumn months [25]. A new blade (leaf - like structure) of sugar kelp used to prepare all three extracts was harvested during summer. Therefore, TPC content was at its highest for this species which is also linked to the age of the seaweed blades (leaf like structures), depth of seaweed cultivation, and access to sunlight [10]. However, sugar kelp was selected for this study due to its high carbohydrate content which gives a pleasant taste and may have potential pro-health properties.

\section{Oxygen Radical Absorbance Capacity (ORAC) assay}

All the Saccharina extracts varied $(\mathrm{p}<0.01)$ in their ORAC values with the highest values for ORAC observed in the hot water and ethanol extracts at $1686 \pm 99$ and $1177 \pm 109 \mu \mathrm{M} \mathrm{T.E} / \mathrm{g}$ dry extract. The cold water extract gave the lowest ORAC values at $259 \pm 37 \mu \mathrm{M}$ T.E/g dry extract (Table 1). The ORAC values were dependent on the polarity of the solvent and the applied temperature during the extraction processes, which is in agreement with previously reported research [10]. Properties of scavenging reactive oxygen species (ROS) increased with polarity and temperature of the extraction. Measurements confirmed that the hot water extraction gave extracts with the highest antioxidant content. Cold water extracts were not as rich in antioxidant compounds. Saccharina latissima did not present very high capacity to scavenge peroxyl radicals compared to other brown seaweeds species such as Fucus vesiculosus and Fucus serratus [10]. However, Wang et al. demonstrated results [10] which were confirmed by our in this study that the extraction method plays a key role in extract composition and properties. As mentioned above, organic solvents such as acetone give extracts which are comparatively high in antioxidant compounds but may contain residual solvents that are hazardous to the cells used for the in vitro cell cultures in the bioactivity measurements and may be less desirable for many commercial applications, especially with the increased demand for components obtained by "greener" production methods. The data correspond well with observations, demonstrating that polyphenols and carbohydrates are efficient in scavenging free radicals $[26,27]$.

\section{Cell viability assessment}

The 2,3-Bis(2-methoxy-4-nitro-5-sulfophenyl)-2H-tetrazolium-5-carboxanilide

(XTT) cytotoxicity assay was performed to evaluate whether extracts could safely be applied to macrophages. The quality of the extracts is a key issue while working with in vitro cell models due to cellular sensitivity toward toxins, organic solvents residues, and other impurities that may negatively impact the viability of cultured cells. The hot water extract did not significantly decrease proliferation of THP-1 macrophages at 1 and $10 \mu \mathrm{g} / \mathrm{ml}$ concentrations (Fig. 1) where viability was $90 \pm 14 \%$ and $83 \pm 11 \%$ compared to the control at $100 \%$. 


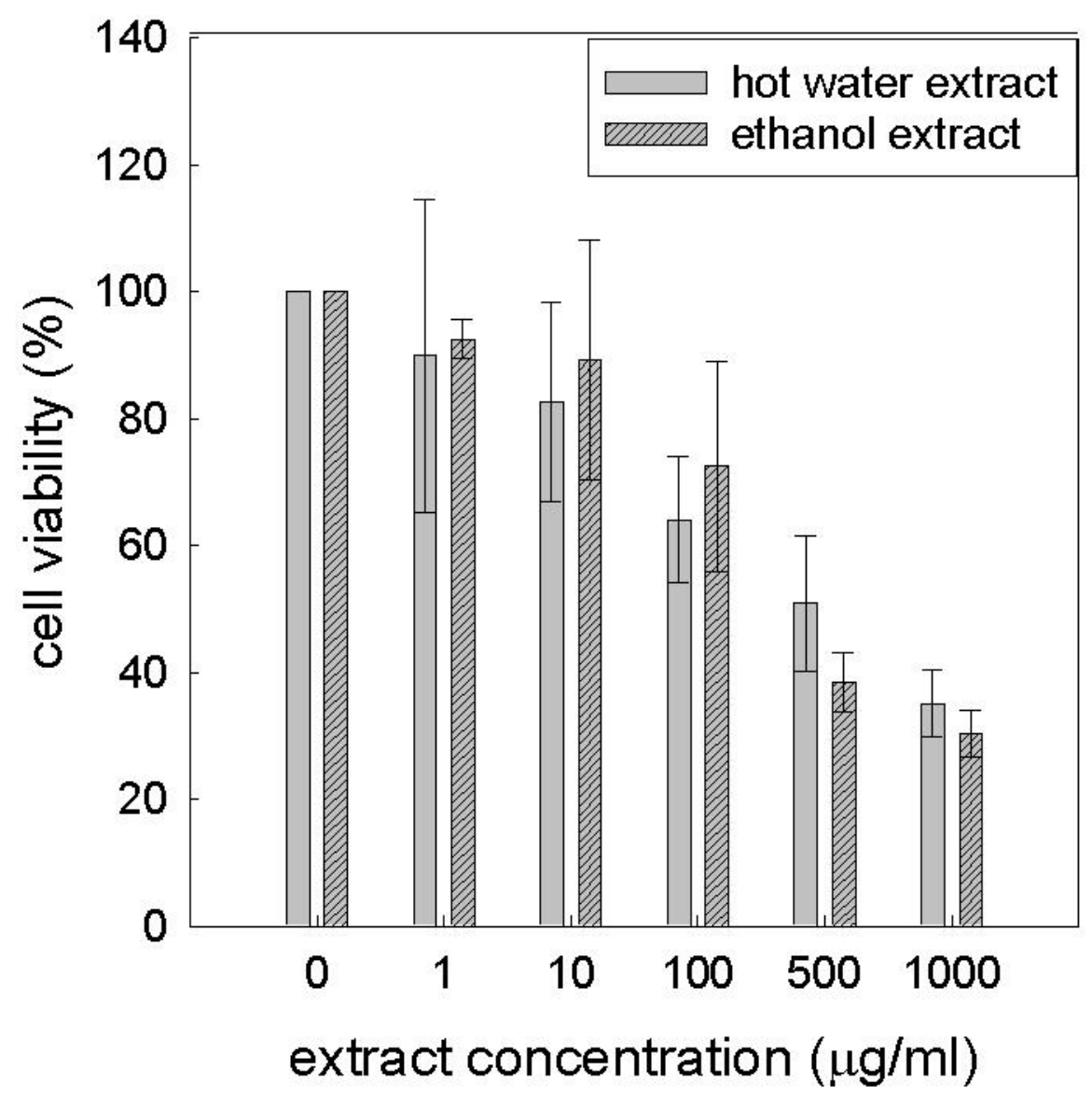

Figure 1. Cellular viability assessed with XTT proliferation assay in the presence of hot-water and ethanol extracts $(n=3)$.

However, the cell viability decreased from $64 \pm 7 \%$ to $35 \pm 3 \%$ in the hot water extracts at 100 to $1000 \mu \mathrm{g} / \mathrm{ml}$. Similarly, cell viability was not affected by application of ethanol extracts at 1 and $10 \mu \mathrm{g} / \mathrm{ml}$ concentrations with viability at $92 \pm 2 \%$ and $89 \pm 1 \% \quad(\mathrm{n}=3, \mathrm{p} \geq 0.25)$ respectively. The cytotoxic effect of ethanol was reduced to $73 \pm 12 \%$ at $100 \mu \mathrm{g} / \mathrm{ml}$ and was reduced to $30 \pm 2 \%$ at $1000 \mu \mathrm{g} / \mathrm{ml}$. The XTT results corresponded well with the microscopic observations and indicates decisive cytotoxicity of the hot water and ethanol extracts at $\geq 100$ $\mu \mathrm{g} / \mathrm{ml}$ concentrations (Fig. 2). In contrast to the hot water and ethanol extracts, cold water extracts were much more cytotoxic to the cells, even at low concentrations $(10 \mu \mathrm{g} / \mathrm{ml})$ evaluated by microscope (Fig. 2). Accordingly, they were not evaluated further with the XTT proliferation assay. The observed cytotoxic effect of the hot water and ethanol extracts could be caused by generation of ROS by activated macrophages that lead to oxidative stress affecting the cell membrane integrity causing the cell damage [28]. The cytotoxicity of the cold water extracts might have been caused by the presence of microbial toxins and environmental impurities on the surface of the seaweed samples, rather than ROS generation. Increased temperature during extraction or use of $70 \%$ ethanol is known to minimize the presence of microbial flora, especially spores, on the surface of seaweed tissue, improving safety of derived extracts towards macrophages [29]. 


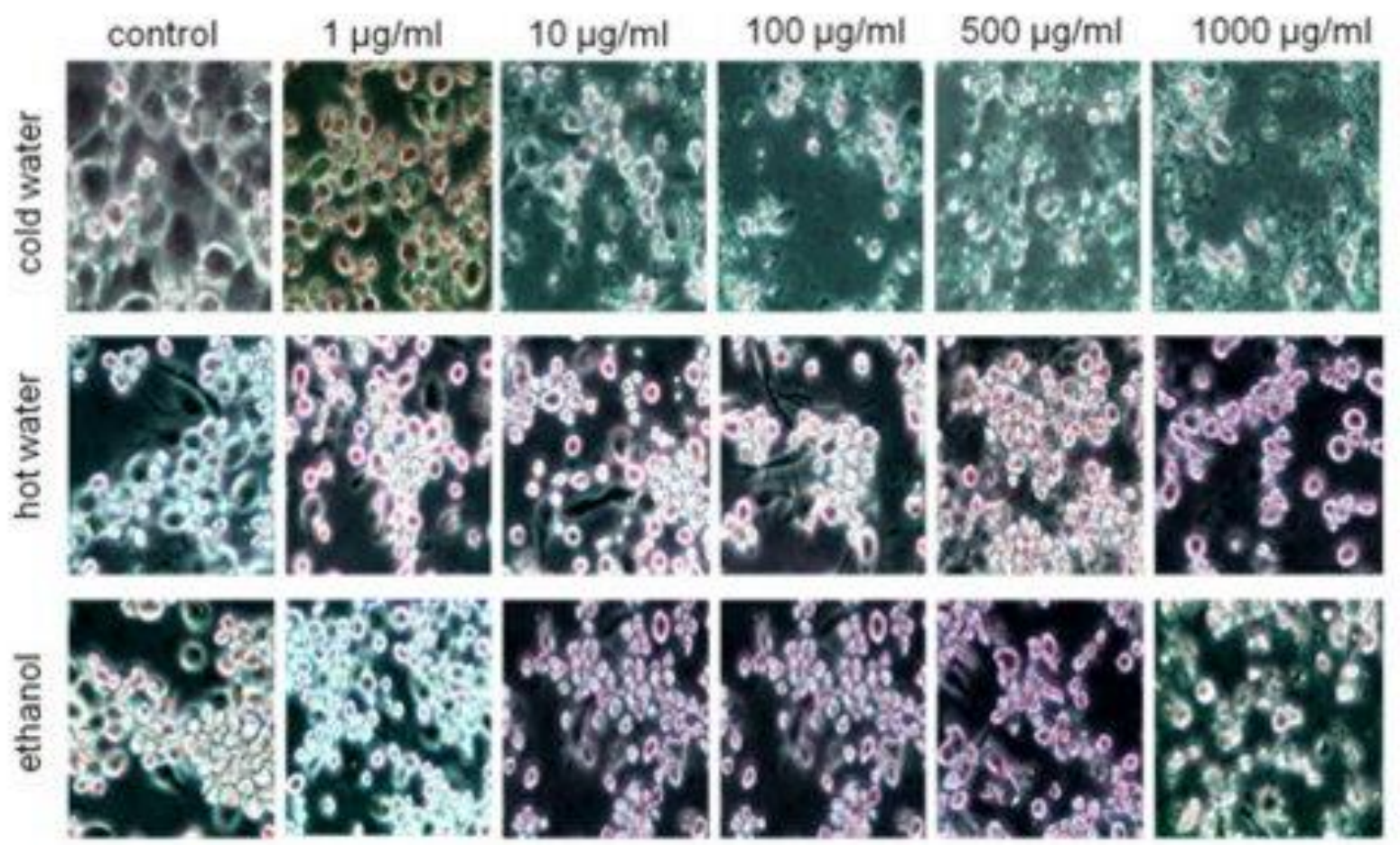

Figure 2. Microscopic pre-evaluation of cellular viability in the presence of cold-water, hotwater and ethanol extracts after $24 \mathrm{~h}$ incubation with Saccharina extracts.

\section{Cytokine secretion into media}

Bioactivity of hot water and ethanol extracts toward macrophages was evaluated by ELISA. Cytokine secretion was interpreted as an indication of bioactivity of extracts toward macrophages. We determined secretion of pro-inflammatory cytokines such as the tumor necrosis factor- $\alpha(\mathrm{TNF}-\alpha)$ and interleukin-6 (IL-6), followed by secretion of antiinflammatory cytokine interleukin-10 (IL-10). Both extracts induced secretion of proinflammatory cytokine $\mathrm{TNF}-\alpha$ at $100 \mu \mathrm{g} / \mathrm{ml}$ suggesting immune modulatory properties of both the hot water and ethanol extracts [30]. The cell viability was not reduced until extract concentration was at $100 \mu \mathrm{g} / \mathrm{ml}$ (Fig.1). Therefore, the TNF- $\alpha$ extracts were not tested at the lower concentrations.

The TNF $-\alpha$ for hot water extract increased from $197 \pm 38 \mathrm{pg} / \mathrm{ml}$ at $100 \mu \mathrm{g} / \mathrm{ml}$ to $1625 \pm 127$ $\mathrm{pg} / \mathrm{ml}$ at $500 \mu \mathrm{g} / \mathrm{ml}$ (Fig. 3) but was reduced again at a higher concentration of $1000 \mu \mathrm{g} / \mathrm{ml}$. This may possibly be linked to the extract cytotoxicity, resulting in decreased number of cells. The ethanol extract also induced secretion of TNF- $\alpha$ to $594 \pm 5$ at $100 \mu \mathrm{g} / \mathrm{ml}$ with an increase to $1120 \pm 44 \mathrm{pg} / \mathrm{ml}$ at $500 \mu \mathrm{g} / \mathrm{ml}$ concentrations (Fig. 3) and was also reduced at higher concentration. The tumor necrosis factor is known for its regulatory activities, triggering secretions of other cytokines such as IL -1 and IL-6, growth factors (transforming growth factor $\beta$, platelet derived growth factor) and hormones such as adrenaline [31]. TNF- $\alpha$ counteracts infection, mediating the inflammation, by increase of migration of phagocytes into tissue [32]. However, excessive secretion of this pro-inflammatory cytokine might lead to inflammatory diseases [33]. 


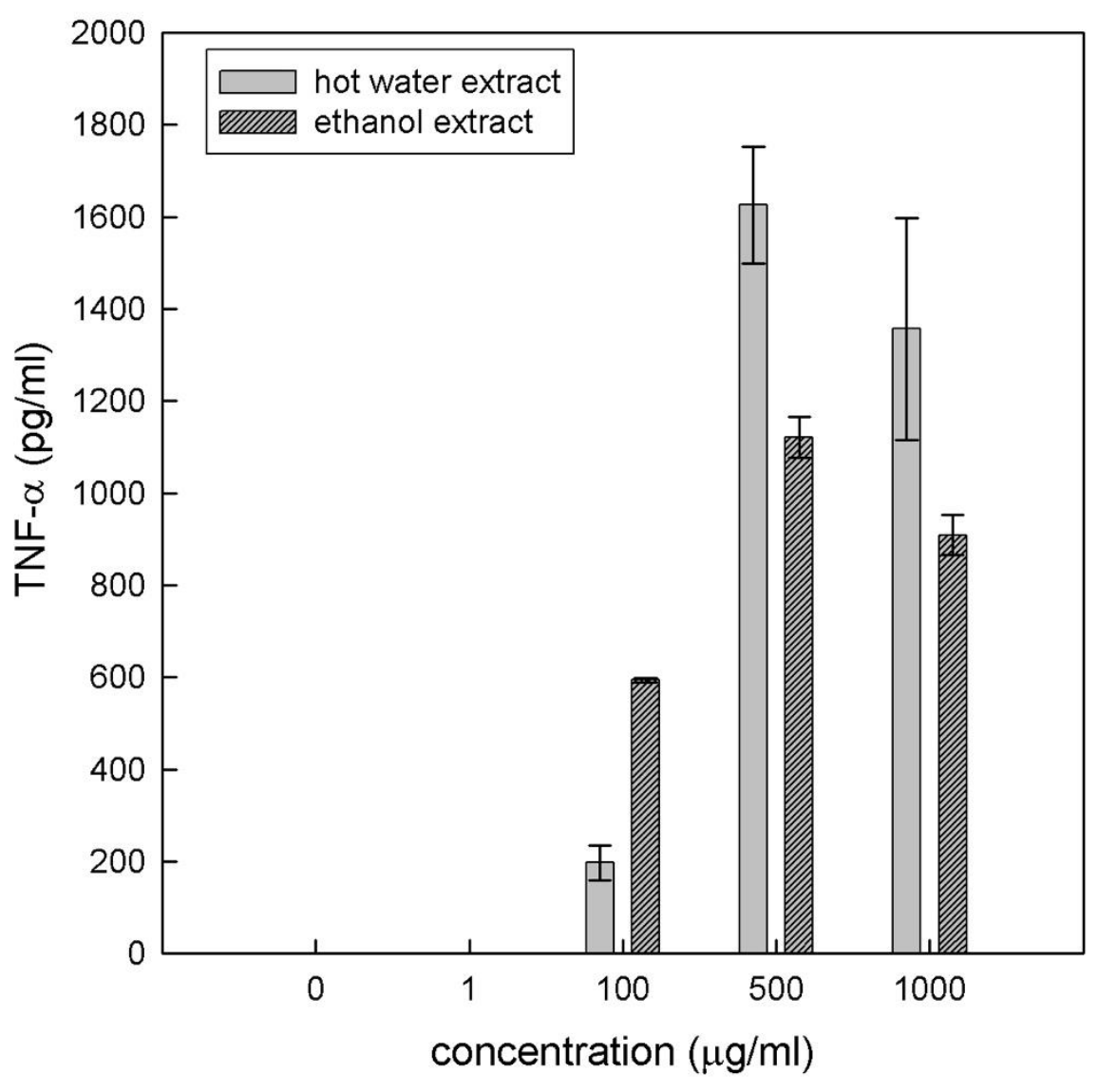

Figure 3.

Secretion of proinflammatory cytokine TNF- $\alpha$ from THP-1 cells in the presence of hot-water and ethanol extracts $(n=3)$.

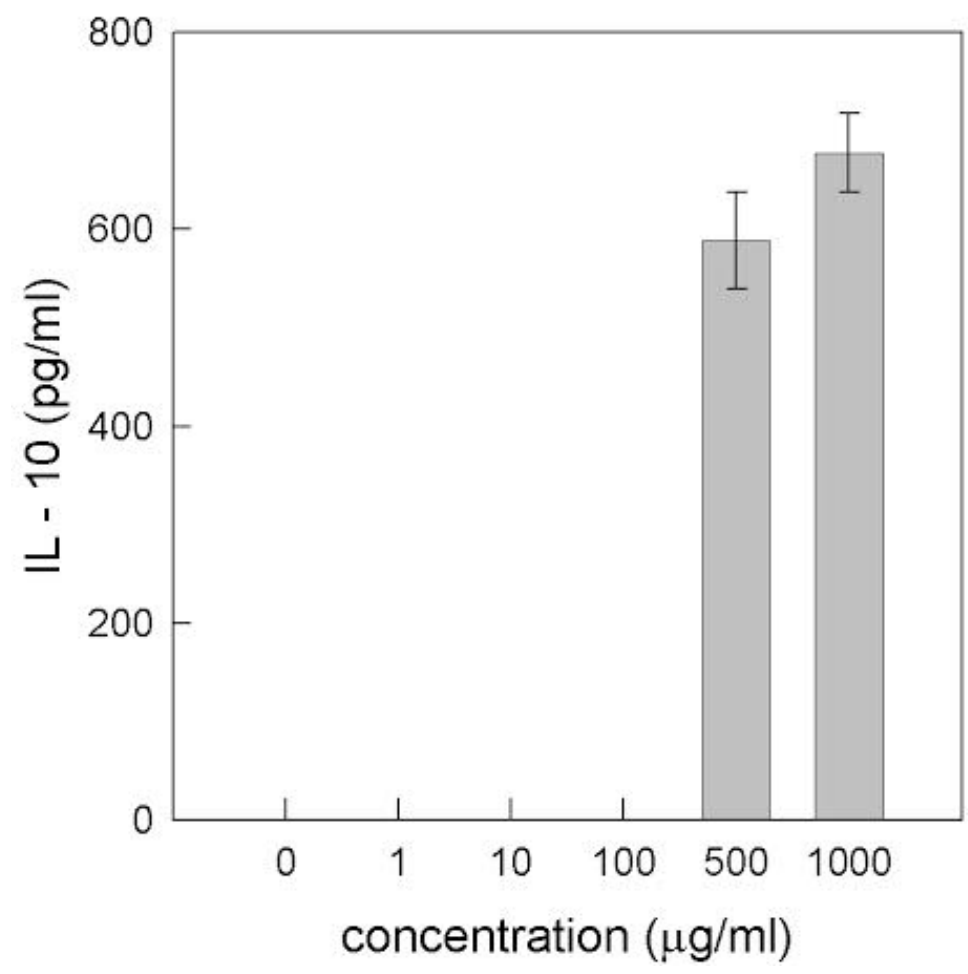

Figure 4. Secretion of anti-inflammatory cytokine IL-10 from THP-1 cells in the presence of hot-water extract $(n=3)$. 
Interleukin-6 is a cytokine involved in various biological processes including inflammation and immune regulation [34]. IL-6 is necessary for life functions, but similar to $\mathrm{TNF}-\alpha$, its continued elevated levels may lead to inflammation diseases [35]. Moreover, excessive levels of IL-6 are secreted in the presence of endotoxins [36]. Endotoxins are present in cell membranes of Gram negative bacteria and contain lipopolysaccharides (LPS) that show very strong toxic properties [37]. In this research, none of the extracts triggered secretion of pro-inflammatory cytokine IL-6. No secretion of IL-6 may indicate that hot water and ethanol extracts were not contaminated with endotoxin and therefore more safe toward macrophages [36].

Interleukin-10 is anti-inflammatory cytokine, which secretion appears as a response to presence of pro-inflammatory cytokines including TNF- $\alpha$ and IL-6. Secretion of IL-10 was observed only for hot water extracts at 500 and $1000 \mu \mathrm{g} / \mathrm{ml}$ concentrations (588 \pm 49 and 678 \pm $40 \mathrm{pg} / \mathrm{ml}, \mathrm{p}=0.3$ ) (Fig. 4). The ethanol extracts did not induce IL-10 secretion at detectable levels. Anti - inflammatory cytokine IL-10 was secreted after application of 500 and 1000 $\mu \mathrm{g} / \mathrm{ml}$ of hot water extracts indicating positive bioactivity of the extract towards human cells.

\section{CONCLUSION}

The present study suggests that carbohydrate enriched extracts from Icelandic edible seaweed Saccharina latissima have antioxidant and immunomodulatory properties towards human THP-1 derived macrophages. The carbohydrate and polyphenol content correlated with ORAC values confirming antioxidant properties of the extracts. The hot water extract affected the proinflammatory $(\mathrm{TNF}-\alpha)$ and anti-inflammatory ( $\mathrm{IL}-10)$ cytokine secretion in macrophages, suggesting their bioactivity through immunomodulatory actions. Both the hot water and ethanol extracts had low cytotoxic effects rendering them safe for human macrophages and therefore may be used in functional foods and high end cosmetics.

Competing Interests: The authors have no financial interests or conflicts of interest.

Authors' Contributions: All authors contributed to this study.

List of Abbreviations: THP-1, is a human monocytic cell line; ORAC, Oxygen Radical Absorbance Capacity; XTT proliferation assay, 2,3-Bis(2-methoxy-4-nitro-5-sulfophenyl)2H-tetrazolium-5-carboxanilide (XTT) proliferation assay; ELISA, Enzyme-linked immunosorbant assays; TPC, Total Polyphenol Content; TNF- $\alpha$, tumor necrosis factor $\alpha$; IL6, interleukin 6; IL-10, interleukin 10; PMA, phorbol 12 - myristate 13 - acetate; AAPH, 2,2'Azobis(2-methylpropionamidine) dihydrochloride; PBS, phosphate buffer saline; FBS, fetal bovine serum; GAE, gallic acid equivalent; MT.E, Moles of Trolox Equivalent.

Acknowledgments and Funding: We acknowledge the University of Iceland Research Fund for funding. We acknowledge Dr Hordur Kristinsson and Dr Magnea G. Karlsdottir from Matis ohf. Reykjavik, Iceland for access to the laboratory facilities and Irek Klonowski from Matis ohf., Reykjavik, Iceland for freeze drying extracts. We also acknowledge Dr Leifur Thorsteinsson from The Blood Bank, Landspitali University Hospital, Reykjavik, Iceland for guidance with cell cultures. 


\section{REFERENCES}

1. Farvin SKH, Jacobsen C: Phenolic compounds and antioxidant activities of selected species of seaweeds from Danish coast. Food Chemistry 2013, 138(2-3): 1670-1681.

2. Suhaila M, Siti Nadia H, Hafeedza Abdul R: Seaweeds: A sustainable functional food for complementary and alternative therapy. Trends in Food Science and Technology, 2012, 23(2): 83-96.

3. Ito K, Hori K: Seaweed: chemical composition and potential food uses. Food Rev Intern 1989, 5: 101-144.

4. Pise NM, Pise AB: Sabale Biochemical Composition of Seaweeds along Central West Coast of India. Pharmacognosy Journal 2010, 2(7): 148-150.

5. Syad AN, Shunmugiah KP, Kasi PD: Seaweeds as nutritional supplements: Analysis of nutritional profile, physicochemical properties and proximate composition of G. acerosa and S. wightii. Biomedicine and Preventive Nutrition 2013, 3(2): 139-144.

6. Broch O, Slagstad D: Modelling seasonal growth and composition of the kelp Saccharina latissima. Journal of Applied Phycology 2012, 24(4): 759-776.

7. Mouritsen O, et al.: Seaweeds for umami flavour in the New Nordic Cuisine. Flavour 2012, 1(1): 4.

8. Van Netten, et al.: Elemental and radioactive analysis of commercially available seaweed. Science of The Total Environment 2000, 255(1-3): 169-175.

9. Gómez-Ordonez E, Jiménez-Escrig A, Ruperez P. Molecular weight distribution of polysaccharides from edible seaweeds by high-performance size-exclusion chromatography (HPSEC). Talanta 2012, 93: 153-159.

10. Wang T, Jonsdottir R, and Olafsdottir G: Total phenolic compounds, radical scavenging and metal chelation of extracts from Icelandic seaweeds. Food Chemistry 2009, 116(1): 240-248.

11. Gupta S, Abu-Ghannam N: Recent developments in the application of seaweeds or seaweed extracts as a means for enhancing the safety and quality attributes of foods. Innovative Food Science and Emerging Technologies 2011, 12(4): 600-609.

12. Floreto E, Teshima S: The fatty acid composition of seaweeds exposed to different levels of light intensity and salinity. Bot Mar 1998, 41: 467-481.

13. El-Said G, El-Sikaily A: Chemical composition of some seaweed from Mediterranean Sea coast, Egypt. Environmental Monitoring and Assessment 2013, 185(7): 6089-6099.

14. Chanput W, Mes JJ, Wichers HJ: THP-1 cell line: An in vitro cell model for immune modulation approach. International Immunopharmacology 2014, 23(1): 37-45.

15. Kurosaka K, Watanabe N, Kobayashi Y: Production of Proinflammatory Cytokines by Phorbol Myristate Acetate-Treated THP-1 Cells and Monocyte-Derived Macrophages After Phagocytosis of Apoptotic CTLL-2 Cells. The Journal of Immunology 1998, 161(11): 6245-6249. 
16. Aderem A, Ulevitch RJ: Toll-like receptors in the induction of the innate immune response. Nature 2000, 406(6797): 782-787.

17. Burns JJ, et al.: The influence of traditional herbal formulas on cytokine activity. Toxicology 2010, 278(1): 140-159.

18. Stow JL, et al.: Cytokine secretion in macrophages and other cells: Pathways and mediators. Immunobiology 2009, 214(7): 601-612.

19. Masuko T, et al.: Carbohydrate analysis by a phenol-sulfuric acid method in microplate format. Analytical Biochemistry 2005, 339(1): 69-72.

20. Turkmen N, et al.: Effect of Extraction Conditions on Measured Total Polyphenol Contents and Antioxidant and Antibacterial Activities of Black Tea. Molecules 2007. 12(3): 484-496.

21. Ganske F, Dell EJ: ORAC Assay on the FLUOstar OPTIMA to Determine Antioxidant Capacity. BMG LABTECH 2006, 12.

22. Handa A, et al.: Seasonal- and depth-dependent growth of cultivated kelp (Saccharina latissima) in close proximity to salmon (Salmo salar) aquaculture in Norway. Aquaculture 2013, 414-415: 191-201.

23. Cho SH et al.: The Antioxidant Properties of Brown Seaweed (Sargassum siliquastrum) Extracts. Journal of Medicinal Food 2007, 10(3): 479-485.

24. Rajauria G, et al.: Antioxidant capacity and polyphenol content of brown seaweeds after heat processing. In Poster presented at 2nd International Chester Food Science and Technology Conference. Chester, UK; 22-24 March 2010.

25. Connan S, et al.: Interspecific and temporal variation in phlorotannin levels in an assemblage of brown algae. Botanica Marina 2005, 47(5): 410-416.

26. Burtin P, et al.: Brown seaweed polyphenols as novel antioxidants for better health and food quality. In Polyphenols communications. Edited byA. Hoikkala, O. Soidinsalo, K. Wahala. Jyvaskyla, Finland; 2004: 139-140.

27. Lu J, et al.: The antioxidant capacity of polysaccharide from Laminaria japonica by citric acid extraction. International Journal of Food Science and Technology 2013, 48(7): 1352-1358.

28. De la Haba C, et al.: Effect of oxidative stress on plasma membrane fluidity of THP-1 induced macrophages. Biochimica et Biophysica Acta (BBA) - Biomembranes 2013, 1828(2): 357-364.

29. Gupta S, Rajauria G, Abu-Ghannam N: Study of the microbial diversity and antimicrobial properties of Irish edible brown seaweeds. International Journal of Food Science and Technology 2010, 45(3): 482-489.

30. Singh U, et al.: Development of an In Vitro Screening Assay to Test the Antiinflammatory Properties of Dietary Supplements and Pharmacologic Agents. Clinical Chemistry 2005, 51(12): 2252-2256. 
31. Goswami B, et al.: TNF- $\alpha / \mathrm{IL}-10$ ratio and C-reactive protein as markers of the inflammatory response in CAD-prone North Indian patients with acute myocardial infarction. Clinica Chimica Acta 2009, 408(1-2): 14-18.

32. Murphy K: Janeway's Immunology. 8th edition. New York: Garland Science; 2012.

33. Liu Y, et al.: Anti-inflammatory effects of several plant extracts on porcine alveolar macrophages in vitro. Journal of Animal Science 2012, 90(8): 2774-2783.

34. Kishimoto T: IL-6: from its discovery to clinical applications. International Immunology 2010, 22(5): 347-352.

35. Fernando MR, et al.: The Pro-Inflammatory Cytokine, Interleukin-6, Enhances the Polarization of Alternatively Activated Macrophages. PLoS ONE 2014, 9(4): e94188.

36. Lieder R, et al.: Endotoxins affect bioactivity of chitosan derivatives in cultures of bone marrow-derived human mesenchymal stem cells. Acta Biomaterialia 2013, 9(1): 47714778.

37. Beutler B: Endotoxin, Toll-like receptor 4, and the afferent limb of innate immunity. Current Opinion in Microbiology 2000, 3(1): 23-28. 